\title{
Surgical ablation explained
}

Vinay Badhwar, MD

\footnotetext{
From the Department of Cardiovascular and Thoracic Surgery, West Virginia University, Morgantown, WVa. Disclosures: Author has nothing to disclose with regard to commercial support.

Received for publication Aug 5, 2018; accepted for publication Aug 10, 2018; available ahead of print Oct 5, 2018.

Address for reprints: Vinay Badhwar, MD, Department of Cardiovascular and Thoracic Surgery, West Virginia University, 1 Medical Center Drive, Morgantown, WV 26506-8059 (E-mail: vinay.badhwar@wvumedicine. org).

J Thorac Cardiovasc Surg 2019;157:583

$0022-5223 / \$ 36.00$

Copyright (c) 2018 by The American Association for Thoracic Surgery

https://doi.org/10.1016/j.jtcvs.2018.08.011
}

The addition of surgical ablation to an appropriate mitral operation with atrial fibrillation is a Class I recommendation. ${ }^{1-3}$ Nevertheless, adoption rates lag because hesitancy or confusion persists with respect to how and why one does the lesions of the Cox-maze operation. ${ }^{4}$ Recent operative attempts at non-Maze lesion set modifications have come at the expense of clinical and electrophysiologic outcome.

In this important contribution by James Cox and co-authors, ${ }^{5}$ each lesion of the contemporary Cox-maze operation is explained in electrophysiologic terms. If the full biatrial lesion set is dutifully performed via sternotomy or minimally invasive open techniques, this article clearly outlines why consistent electrophysiologic success is readily achievable. This guide may further serve to assist both beginning and experienced arrhythmia surgeons on the importance of each lesion and how best to perform them. It may further aid our electrophysiology partners in the complete understanding of what is achievable and why.

Although many recent surgical ablation modifications and hybrid solutions have been introduced, few follow the electrophysiologic basis outlined by Cox and colleagues. ${ }^{5}$ This contribution may help guide atrial fibrillation heart teams in making patient-centered therapeutic decisions that target optimal longitudinal clinical and electrophysiologic outcomes.

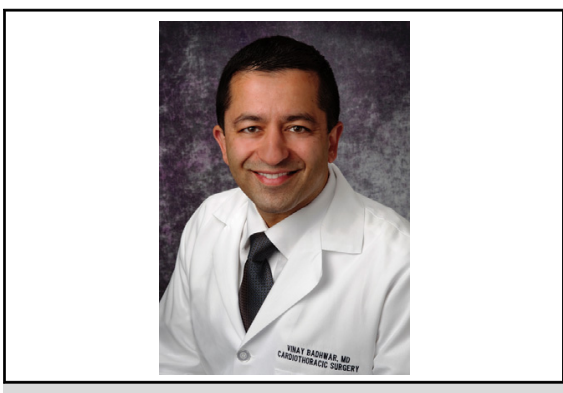

Vinay Badhwar, MD

Central Message

As surgical ablation has become standard practice with clear mortality benefits, some may not fully appreciate the electrophysiologic basis for specific lesions. Dr James Cox attempts to outline each of these lesions and how they impact outcome.

See Article page 584.

\section{References}

1. Calkins H, Hindricks G, Cappato R, Kim YH, Saad EB, Aguinaga L, et al 2017 HRS/EHRA/ECAS/APHRS/SOLAECE expert consensus statement on catheter and surgical ablation of atrial fibrillation. Heart Rhythm. 2017;14: e275-444.

2. Badhwar V, Rankin JS, Damiano RJ Jr, Gillinov AM, Bakaeen FG, Edgerton JR, et al. The Society of Thoracic Surgeons 2017 clinical practice guidelines for the surgical treatment of atrial fibrillation. Ann Thorac Surg. 2017;103:329-41.

3. Ad N, Damiano RJ Jr, Badhwar V, Calkins H, La Meir M, Nitta T, et al. Exper consensus guidelines: examining surgical ablation for atrial fibrillation. J Thorac Cardiovasc Surg. 2017;153:1330-13354.e1.

4. Badhwar V, Rankin JS, Ad N, Grau-Sepulveda M, Damiano RJ, Gillinov AM, et al. Surgical ablation of atrial fibrillation in the United States: trends and propensity matched outcomes. Ann Thorac Surg. 2017;104:493-500.

5. Cox JL, Malaisrie SC, Kislitsina ON, McCarthy PM. The electrophysiologic basis for lesions of the contemporary Maze operation. J Thorac Cardiovasc Surg. 2019; 157:584-90. 